\title{
Differentiatie in de Keel-, Neus- en Oorheelkunde
}

\author{
Citation for published version (APA):
}

Marres, E. H. M. A. (1993). Differentiatie in de Keel-, Neus- en Oorheelkunde. Maastricht University. https://doi.org/10.26481/spe.19930528em

Document status and date:

Published: 28/05/1993

DOI:

10.26481/spe.19930528em

Document Version:

Publisher's PDF, also known as Version of record

\section{Please check the document version of this publication:}

- A submitted manuscript is the version of the article upon submission and before peer-review. There can be important differences between the submitted version and the official published version of record.

People interested in the research are advised to contact the author for the final version of the publication, or visit the DOI to the publisher's website.

- The final author version and the galley proof are versions of the publication after peer review.

- The final published version features the final layout of the paper including the volume, issue and page numbers.

Link to publication

\footnotetext{
General rights Owners
rights.

- You may freely distribute the URL identifying the publication in the public portal. please follow below link for the End User Agreement:

www.umlib.nl/taverne-license

Take down policy

If you believe that this document breaches copyright please contact us at:

repository@maastrichtuniversity.nl

providing details and we will investigate your claim.
}

Copyright and moral rights for the publications made accessible in the public portal are retained by the authors and/or other copyright owners and it is a condition of accessing publications that users recognise and abide by the legal requirements associated with these

- Users may download and print one copy of any publication from the public portal for the purpose of private study or research.

- You may not further distribute the material or use it for any profit-making activity or commercial gain

If the publication is distributed under the terms of Article $25 \mathrm{fa}$ of the Dutch Copyright Act, indicated by the "Taverne" license above, 


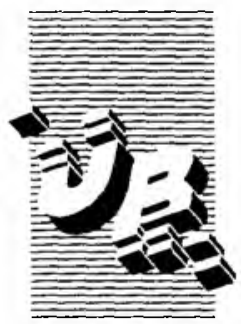

De uitleentermijn verstrijkt op:

\section{2004,1993}

- 2 JAN. 1995

Rijksuniversiteit Limburg

Postbus 616

6200 MO Maastricht

Gelieve deze publicatie tijdig te retourneren of (teleionisch) verlenging van de vitleentermijn aan te vragen 


\section{Differentiatie in de}

\section{Keel-, Neus- en Oorheelkunde}

Rede

Uitgesproken ter gelegenheid van zijn afscheld als gewoon hoogleraar in de Keel-, Neus- en Oorheelkunde aan de Rijksuniversiteit Limburg door

Prof. Dr. E.H.M.A. Marres

op

28 mei 1993 


$$
\frac{p=100337 \mathrm{c} 36}{\text { Bibliongon }}
$$


Geachte Rector Magnlficus, Geachte Collegae, Geachte Toehoorders,

Op 2 jull a.s. Is het honderd jaar geleden, dat de Stichtingsvergadering van de huldige Nederlandse Vereniging voor Keel-, Neus- en Oorheelkunde plaatsvond in het Militair Hospitaal te Utrecht. Op ultnodiging van Prof. Dr. A.A.G. Guye en Prof. Dr. H. Zwaardemaker zijn op dat moment een twintlgtal Nederlandse oorartsen bljeengekomen om te beraadslagen over de oprichting van een Nederlandse Oorheelkundige Vereniging. Tijdens deze vergadering ontspint zich een levendig debat over de naam der vereniging. De heren Nijkamp en Burger stellen namelijk voor haar 'Keel-, Neus- en Oorheelkundige Vereniging' te dopen en in de werkzaamheden gelijke aandacht te geven aan de otologie en laryngologie. De voorstellers van het amendement hechten groot gewicht aan het praktisch voordeel, dat het naar hun mening zou opleveren, otologen, rhinologen en laryngologen te verenigen. Bovendien vormt de pharynx een band tussen de oorheelkunde en laryngologie. De vergadering verenigt zich met elf tegen acht stemmen met het amendement, zodat de vereniging nu 'Keel-, Neus- en Oorheelkundige Vereniging' genaamd is. Aldus het verenigingsverslag.

Niet alleen om $u$ op de hoogte te brengen van het felt, dat binnenkort het honderdjarig bestaan van onze vereniging feestelijk wordt gevlerd, is de reden dat mijn afscheidsrede met deze inleiding begint, maar ook dat het mij de gelegenheid biedt, $u$ in grote lljnen te berichten over de ontwikkelingen binnen de keel-, neus- en oorheelkunde gedurende de laatste 35 jaar, dat lk als specialist in de keel-, neus- en oorheelkunde lid ben van deze vereniging.

Tijdens mijn openbare les, getiteld "Differentlatle in de keel-, neus- en oorheelkunde" uitgesproken in 1970 bij de aanvaarding van de functie van lector in de keel-, neus- en oorheelkunde - in het bijzonder de oorheelkunde aan de Katholieke Universiteit te Nijmegen, schetste Ik, zoals $u$ begrijpen zult, in grote lijnen de geschiedenis en de stand van zaken in de oorheelkunde op dat moment. Tijdens deze afscheidsrede, die dezelfde titel heeft als mijn openbare les, zal lk daarom niet al te diep ingaan op de ontwikkelingen in de oorheelkunde, maar u vooral informeren over de ontwikkelingen betreffende de overige subspecialismen in de keel-, neus- en oorheelkunde gedurende mijn periode als specialist. Vanwege tijdgebrek is het eveneens niet mogelijk in te gaan op het vele wetenschappelijke onderzoek dat gedurende de laatste 
35 jaar in de keel-, neus- en oorheeikunde werd verricht. Ik zal mi] beperken tot de meer praktische en klinische felten betreffende de voorultgang in dlagnostlek en chirurgie.

Om te voorkomen dat $u$, zoals gebrulkelljk bij een afscheidsrede, al of niet behoort te luisteren naar de monoloog van de spreker, zal ik daarblj gebruik maken van de audiovisuele apparatuur, die vandaag in deze aula staat opgesteld vanwege een symposium dat ter ere van mijn afscheld door de door $\mathrm{mlj}$ zeer gewaardeere staf van onze afdeling werd georganiseerd.

\section{Audiologie}

Vooraf aan de behandeling van een patlent die zijn hulsarts of speclalist bezoekt is, zoals bekend, het afnemen van een anamnese noodzakelljk, waarna een goed onderzoek van de patlënt dient plaats te vinden. Klaagt de patiënt bv. over een gehoorvermindering dan is het noodzakelljk dat de mate van zi|n gehoorverlies wordt onderzocht. Destijds, in 1958, toen lk mijn opleiding tot specialist begon, werd na Inspectie van de trommelvliezen en het bekende gehooronderzoek door middel van stemvork en fluisterspraak een toonaudiogram gemaakt. Hierblj wordt de drempel van de luchtgeleiding en beengelelding van het gehoor gemeten om aldus de ernst van een middenoorof binnenoorgehoorverlies te kunnen vaststellen. Hoewel destijds nog niet algemeen gebrulkelijk in de perifere praktijk, werd in de universitaire klinleken reeds een spraakaudiogram gemaakt om een eventueel discriminatieverlies betreffende het spraakverstaan bij de patlënt te diagnostlseren om aldus het profijt van het voorschrijven van een hoortoestel te kunnen voorspellen. Daar men bij het afnemen van oen toon- en spraakaudiogram de medewerking van de patiënt nodlg heeft, omdat hij moet aangeven of hlj al dan nlet de aangeboden toon hoort of de spraak verstaat, rekent men deze vorm van gehooronderzoek tot de subjectleve audiometrle. Naast deze subjectieve audiometrle kwam in de zestig- en zeventiger jaren de objectieve audiometrie tot ontwikkeling. Daar men bij deze vorm van audiometrie de medewerking van de patiënt nlet nodig heeft, spreekt men van objectieve audiometrle. Ik versta hieronder de tympanometrle en de electro-audiometrle (Jewett, 1970; Eggermont, 1974). Door middel van een tympanogram en stapedius reflexmeting (Metz, 1946), tezamen de tympanometrie genaamd, meet men de beweeglijkheld of stijfheid van trommelvlies en gehoorbeentjes (Jerger, 1970). De 
tympanometrie geeft bij afwijkingen in het middenoor belangrijke gegevens die de resultaten van de toon- en spraakaudiometrie kunnen bevestigen en aanvullen. Voorafgaande aan een ooroperatie geeft het onderzoek daarom belangrijke informatie. Ik denk daarbij aan afwijkingen aan de gehoorbeenketen, zoals congenitale afwijkingen en otosclerose. Daarnaast werd het tympanometrlsch onderzoek bij kinderen van groot belang om na te gaan of er al of niet vocht achter het trommelvlies aanwezig is daar de aanwezigheid hiervan bij zeer veel kinderen de oorzaak van een slechthorendheid is.

Bij de electro-audiometrie, bestaande uit de electro-cochleografie on brainstem-evoked-response audiometrie, wordt een electrische response op geluid gemeten in plaats van het actlef waarnemen van een toon of spraak bi] de toon- en spraakaudiometrie. Om twee redenen is deze vorm van audiometrie van belang. In de eerste plaats is het door deze methode van gehooronderzoek mogelijk de perifere oorfunctie van een kind reeds in de eerste levensmaanden te bepalen en in de tweede plaats kan men bij een perceptie slechthorendheid differentiëren tussen een cochleair of retrocochlealr gelegen gehoorverlies. De electro-audiometrie is vooral van belang bij de differentiaal diagnostiek bij patiënten met een eenzijdig perceptief gehoorverlies daar men via deze meetmethode de oorzaak van dit verlies kan vaststellen. Ik denk daarbij aan de patiënt met een eenzijdige ziekte van Menière of brughoektumor.

Betreffende de jaren die achter mij liggen, wijs ik u ook op het grote belang van de officiële erkenning van de perifere audiologische centra (Commissie Köster, 1972) naast de universitaire audiologische centra, ontstaan in de vijftiger jaren.

Gaarne memoreer ik eveneens de invoering van de Ewing-test bij de zuigelingenbureaux in 1963, waardoor het mogelijk is een indruk te krljgen van het gehoor van kinderen tussen de 7 en 13 maanden. Het gehoor van deze jonge kinderen wordt bij deze test door middel van geluidgevend speelgoed onderzocht. ik verwacht echter dat in de toekomst deze test, welke per kind veel tljd vergt, vervangen zal worden door het meten van oto-acustische emissies volgens Kemp bij nog jongere kinderen. 
Dit gedeelte van miln rede afsluitend, breng ik $u$ in herinnering de ontwikkeling van het moderne hoortoestel. In de jaren zestig kreeg de patiënt, indien hij een hoortoestel nodig had, nog een zgn. kasttoestel. Nu draagt hij meestal achter het oor of in het oor een toestel, terwijl op dit moment de peritympanische hoortoestellen in ontwikkeling zijn. Eveneens is bekend dat in Japan geëxperimenteerd wordt met hoortoestellen, die in het middenoor kunnen worden geïmplanteerd. Patiënten bij wie een hoortoestel om verschillende redenen niet in de gehoorgang kan worden aangepast, kunnen nu bovendien worden geholpen door middel van een hoorbril of door een toestel, dat door middel van een schroef achter het oor kan worden gefixeerd. Daarnaast zijn sommige totaal dove patiënten te helpen met een implantaat in de cochlea.

Het belang van een goede zorg en diagnostiek bij patiënten met een gehoorprobleem moge tenslotte blijken uit het feit, dat bij ongeveer vijf duizend van de $\mathbf{2 5 . 0 0 0}$ patiënten die onze polikliniek jaarlijks bezoeken, \pm 11.000 diverse audiometrische onderzoeken plaatsvinden.

\section{Vestibulologie}

Duizeligheid is een klacht, die in de huisartspraktijk zeer vaak wordt gehoord. Voor drie à vier procent van de patiënten die hun huisarts bezoeken, is het de hoofdklacht. In Nederland worden per jaar tussen de 400.000 en 500.000 consulten verricht waarbij de diagnose vertigo is. Van deze patiënten wordt $15 \%$ naar een specialist verwezen. Oosterveld omschrijtt het begrip duizeligheid als een illusie van het ondergaan van bewegingspatronen. Het is het ervaren van een instabiliteit van de omgeving. Duizeligheid wordt beschouwd als een symptoom, evenals koorts en hoofdpijn dat zijn. Het is dus geen ziektebeeld. De klacht duizeligheid vereist vanzelfsprekend wel onderzoek, hoewel het bij $\mathbf{4 0 \%}$ van de patlënten nlet mogelijk is, zelfs met een zeer uitgebreid onderzoek, de oorzaak ervan vast te stellen. Ongeveer honderd ziektebeelden kunnen vergezeld gaan van duizeligheid, aldus Oosterveld. Het evenwichtsstelsel wordt gevormd door een multisensorisch systeem. Op grond van visuele, vestibulaire, proprioceptieve en andersoortige zintuiglijke Informatie regelt het evenwichtsstelsel het in stand houden van het evenwicht bij stilstand en beweging, de blikstabilisatie tijdens hoofdbewegingen en 
ruimtelljke oriëntatie volgens een samenvatting van mijn medewerker Kingma. Als de informatie uit de verschillende zintuigsystemen niet goed met elkaar overeenstemt en er dus sprake is van een sensorisch conflict, kunnen evenwichtsstoornissen, visusstoornissen en duizeligheid ontstaan. Veel onderzoekers in Nederland hebben in het verleden een belangrijke bljdrage geleverd tot een betere kennis van het functioneren van het evenwlchtsstelsel. Ik noem de namen van Quix, Magnus en de Kleyn, Versteegh, Jongkees, Groen, van Egmond en heden ten dage Oosterveld en Kingma. Gezien de gecompliceerdheid van een volledig evenwichtsonderzoek, dat bij een patiënt ongeveer twee uur in beslag neemt, kan ik hierop in deze rede vanzelfsprekend niet uitgebreld ingaan. Naast de vestlbulo-spinale testen en andere methoden voor de bestudering van evenwicht en oriëntatie, kan het vestibulaire systeem op grond van haar cruciale rol bij de sturing van oogbewegingen ook worden nagegaan door meting en analyse van oogbewegingen. De registratie van oogbewegingen kan door middel van een eenvoudige registratie-recorder plaatsvinden, hetgeen het geval was tijdens mijn opleiding. Tegenwoordig echter, en hiermee wil lk volstaan, biedi de rechtstreekse data-acquisitie met behulp van de computer aanmerkelijke voordelen door de mogelijkheid tot een uitgebreidere en snellere analyse van de oogbewegingen dan voorheen. Ook kan een automatisering plaatsvinden van de verwerking van onderzoeksgegevens verkregen via het reeds lang bekende electronystagmografisch onderzoek en van de moderne optische detectie van oogbewegingen door middel van een infrarode videocamera en eveneens van de enkele en dubbele magnetische inductie methode.

Blj onze afdeling Vestibulologie vinden op dit moment jaarlijks ongeveerd duizend evenwichtsonderzoeken plaats.

\section{Radiodiagnostiek}

Een zeer belangrijke ontwikkeling bij de diagnostiek van afwijkingen in mijn specialisme komt van de kant van de radiologie. Ik herinner me nog goed dat ik in 1959, als jonge assistent in opleiding, mijn eerste voordracht hield voor onze keel-, neus- en oorheelkundige vereniging over het belang van het planigrafisch onderzoek van het rotsbeen, een onderzoeksmethode welke nu reeds lang obsoleet is. Sindsdien is er op radiologisch terrein zeer veel 
veranderd. In 1972 werd namelijk de computertomografie of CT-scan wereldkundig gemaakt en werden er in de tweede helft van de zeventiger jaren in meerdere radiologische centra CT-scanners geplaatst. De CT werd voor het onderzoek van schedel en hals voor de keel-, neus- en oorheelkunde onmisbaar. Ditzelfde is het geval voor de in de tachtiger jaren tot ontwikkeling gekomen Kernspintomografie of magnetische resonantie beeldvorming, de MRI genoemd, een afkorting van Magnet/c Resonance Imaging. Pathologie in schedel en hals kan door deze methode van onderzoek haarfijn worden afgebeeld. Ik denk daarbij met betrekking tot mijn specialisme aan het zichtbaar maken van de brughoek in de achterste schedelgroeve en oncologische afwijkingen in de hals. Men kan stellen dat de komst van CT en MRI voor de keel-, neus- en oorheelkunde van groot belang is geweest.

Het klinische werk in de keel-, neus- en oorheelkunde werd in de laatste jaren eveneens sterk beïnvloed door de vooruitgang op verschlllende andere gebieden der geneeskunde. Ik denk daarbij aan de klinische bacteriologie (o.a. de resistentie bepalingen van bacteriën), de immunologie, de radiotheraple, de pathologische anatomie en de snelle ontwikkeling van de anaesthesiologie.

\section{Otologie}

In de oorheelkunde, het subspecialisme binnen de keel-, neus- en oorheelkunde, waarop vooral mijn aandacht en interesse voortdurend gericht was en $\mathrm{mlj}$ bovendien zeer veel voldoening heeft gegeven, zijn er tijdens mijn loopbaan zoveel ontwikkelingen geweest dat ik me, hoewel dit mij moeite kost, dien te beperken door er enkele ervan tijdens deze rede te vermelden. Allereerst noem ik het ontstaan van de reconstructieve middenoorchirurgie tljdens de vijftiger jaren. Voorafgaande aan deze jaren werd met name een chirurgische ingreep van het rotsbeen vooral uitgevoerd om pathologische processen uit te ruimen. Ik zal hier niet op ingaan. In de decennia daarna kwam dankzij het gebruik van de operatie-microscoop tijdens ooroperaties de gehoorherstellende chirurgie tot grote bloei. De firma Zeiss ontwikkelde de eerste microscoop, speciaal bestemd voor de oorchirurgie en deze werd door Jongkees gedemonstreerd tijdens het vijfde wereldcongres betreffende de keel-, neus- en oorheelkunde te Amsterdam in 1953. Het zijn Wullstein en 
Zöllner geweest, die eveneens tijdens dit congres, de chirurgische principes van diverse tympanoplastieken beschrijven. In de moderne middenoorchirurgie worden sindsdien autologe, homologe en heterologe transplantaten gebruikt om de middenoorfunctie en dus het gehoor te herstellen bil patiënten die tengevolge van een doorgemaakte middenoorontsteking een gehoorverlies hebben gekregen. Heermann (1958) propageerde als eerste het gebruik van autologe fascie van de musculus temporalls om een trommelvliesperforatie te sluiten. Domenech (1959) gebruikte hiervoor periost, Shea en Tabb (1960) beschreven het gebruik van vene als underlay en Goodhill (1964) perichondrium van de tragus. Als homoloog materiaal voor een herstel van het trommeivlies noem ik perichondrium, kraakbeen, dura, etc. Voor het eerst werd bovendien een homoloog trommelvlles getransplanteerd door Chalat in 1964 en werd in 1964 voor het eerst een trommelvlies tezamen met de gehele gehoorbeenketen overgebracht bij een patiënt door Betov ult Berlijn. Deze techniek werd op grote schaal toegepast en gepropageerd door Marquet uit Antwerpen in 1966. Losse homologe gehoorbeentjes, heden ten dage een veel gebruikte techniek, werden in 1959 door Portman getransplanteerd om de gehoorbeenketen van een patiënt te herstellen. Daarnaast kwamen de heterologe prothesen in gebrulk, o.a. gemaakt van hydroxyapetite (Grote, Wehrs) en bioglas (Helms). Ditzelfde is het geval bij de patiënt met een otosclerose, een aandoening waarbij een middenoor gehoorverlies aanwezig is door een fixatie van de stijgbeugel. Het vervangen van de stijgbeugel door een prothese door Shea (1958), waarbij de meestal nog jonge patiënt, die in $90 \%$ van de gevallen aan beide oren hierdoor slechthorend is, weer goedhorend wordt, geeft de oorchirurg grote voldoening.

Eveneens is de chirurgische behandeling van chronische ontstekingen in middenoor en mastoid tijdens mijn loopbaan zeer veranderd. Zo memoreerde ik reeds de invoering van de tympanoplastieken in 1953 door Wullstein en Zöllner, het is Claus Jansen uit Gummersbach geweest, die in 1957 de zgn. posterieure tympanotomie ofwel de combined approach tympanoplasty meldde. Samenvattend houdt deze chirurgische techniek in, dat de pathologie in middenoor en mastoid via de gehoorgang en mastoid wordt verwijderd waardoor de benige achterwand van de gehoorgang intact blijft. Tegelijkertijd of tijdens een second stage operatie vindt een middenoorreconstructie plaats. Vermeld dient echter te worden, dat in de otologische wereld nog steeds actief op grond van allerlei argumenten wordt gediscussieerd over het voor en tegen 
van deze chirurgische techniek.

In dit beknopte overzicht inzake de otologische chirurgie moet ongetwijfeld ook genoemd worden het plaatsen van trommelvliesbuisjes ter behandeling van patiënten met een otitis media met effusie. Het is de meest voorkomende ingreep in de oorheelkunde. Armstrong begon in 1952 met het plaatsen van trommelvliesbuisjes bij patiënten met deze aandoening. In 1954 publiceerde hij in een artikel van slechts twee pagina's zijn eerste gunstige resultaten bij vijf patiënten. Onze landgenoot Schmidt ontwikkelde 1961 een polyethyleen buisje met dubbele flens. Gezien het zeer frequent voorkomen van deze aandoening worden er alleen al in Nederland jaarlijks enkele tienduizenden trommelvliesbuisjes geplaatst.

Bij één op de tien- à twintigduizend geboorten komt een volledige afsluiting van de gehoorgang, atresle genoemd, aan een zijde voor en bij één op de veertig- à tachtigduizend geboorten is dit aan twee zijden het geval. De reconstructie van de gehoorgang en middenoor door mij na een bezoek aan Ombredamme te Parijs in Nijmegen opgestart en door Cremers aldaar voortgezet, heeft mij sinds de zeventiger jaren zeer geboeid. Vele kinderen, maar helaas niet alle, zijn door ons in Nljmegen en Maastricht met succes geopereerd.

Eduard Sandifort, anatoom te Leiden, beschreef als eerste in 1777 een Klein nervus acusticus neurinoom bij een patiënt post mortem en in 1912 werd door Quix te Utrecht voor het eerst translabyrintair een acusticus neurinoom verwijderd. Na de publicatie van House in 1964 over een grote serie extirpaties van acusticus neurinomen via deze benadering ontstond er wereldwijd een samenwerking tussen neurochirurgen en oorartsen. Ook in Nederland is dit het geval geweest. Na de kliniek van House in Los Angeles twee maal bezocht te hebben, werden door mij en vervolgens door Cremers sinds de zeventiger jaren in Nijmegen en daarna door mij in Maastricht nervus acusticus neurinomen tot een bepaalde grootte eveneens translabyrintair verwijderd. Ook een transtemporale benadering van de tumor, indien deze zich beperkt tot de inwendige gehoorgang, werd te Maastricht en in Nijmegen samen met de neurochirurg een enkele maal uitgevoerd. 
Hoewel de chirurgische behandeling van patiënten met de ziekte van Menière omstreden is, bericht ik tenslotte dat Cremers en ik naar aanleiding van de publicaties van House, Morrison, Portman, Fisch, Pulec en anderen, meer dan honderd patiënten met de ziekte van Menière in Nijmegen en Maastricht met succes chirurgisch hebben behandeld via een saccus endolymphaticus drainage of een translabyrintaire neurectomie van de nervus vestibularis.

De toenemende samenwerking tussen neurochirurgen, otologen en andere specialismen blijkt uit de oprichting van werkgroepen 'schedelbas/schirurgle' op mondiaal, landelijk en universitair niveau, hetgeen eveneens in Maastricht het geval is.

\section{Rhinologle}

Op de historie, voorafgaande aan miln opleiding tot specialist betreffende de functie van de neus als reukorgaan, als filter en bevochtiger van de ingeademde lucht etc., en de functie van de neusbijholten, kan ik helaas niet ingaan, hoewel de literatuur hlerover zeer interessant is. Het is bekend dat de neus een essentleel onderdeel van de tractus respiratorius is, en dat afwijkingen van de normale toestand van de neus een verdergaande invloed hebben dan het veroorzaken van subjectieve klachten over neusverstopping, reukverlies en hoofdpijn. Burger schrljft in zijn intreerede in 1905 reeds: aan het nut van een normale neusademhallng wordt niet meer getwiffeld. In een aantal belangrljke artikelen van Ogura (0.a. 1966, 1968) werd aangetoond dat een passagebelemmering in de neus het ademhalingsmechanisme beïnvloedt. Er werd een afgenomen vitale capaciteit, één secondewaarde en compliance gevonden. Het Is dan ook niet verwonderlijk dat het actieve en passieve functie-onderzoek van de neus door middel van de rhinomanometrie blnnen de rhinologie sinds de zestiger jaren een belangrijke bijdrage levert. Ook het onderzoek van de neus via optieken is heden algemeen in gebruik. 
Jacques Joseph uit Berlijn, naar wie de Joseph Society is genoemd, introduceerde in 1898 de rhinoplastlek. Ongetwijfeld is de rhinoplastiek wat betreft de plastische chirurgie van het gelaat de meest gevraagde en toegepaste operatie. De transnasale correctie van de neus volgens de Amerikaan Cottle wordt sinds het einde van de vijftiger jaren over de hele wereld uitgevoerd, terwijl de zgn. open rhinoplastlek volgens Goodman (Toronto, Canada) sinds de zeventiger jaren steeds meer wordt toegepast, omdat via deze techniek een beter inzicht wordt verkregen op alle anatomische structuren van de neus. Ook in Maastricht wordt deze technlek veelvuldig toegepast en binnenkort zal mijn oud-staflid, collega Zljlker, hierop promoveren. Ook tijdens een rhinoplastiek worden in de neus, indien nodig bij een tekort aan weefsel, vele soorten transplantaten aangebracht.

Tot enkele jaren geleden werden afwijkingen als chronische en of recidiverende sinusitiden en neuspoliepen behandeld met ingrepen zoals de operatie volgens Claoué, Caldwell-Luc en poliepextractie. Deze operaties zijn de laatste jaren vrijwel geheel vervangen door de endoscopische neusbljholtenchlrurgle. Er zijn vele typen optieken ontwikkeld en het Instrumentarium voor deze vorm van chirurgie werd gedurende de laatste jaren aangepast.

De chirurglsche benadering van de fossa pterygopalatlna, de ruimte dorsaal gelegen van de sinus maxiliaris, van de hypophyse en de chlrurgische behandeling van patiënten met een sleep apneu syndroom kwamen eveneens in de laatste decennla tot ontwikkeling.

De toename in kennis betreffende allergische aandoeningen van het neussiljmulies en de diagnostiek en therapie van deze voor de patiënt zeer belangrijke klacht, is eveneens gedurende de laatste jaren aanzienlijk geweest.

\section{Foniatrie}

Tijdens de eerste inaugurele rede aan deze universiteit, door $\mathrm{mlj}$ uitgesproken op 22 januari 1982, sprak ik met u over de problematiek van het spraak- en taalgestoorde kind. Tijdens deze rede bepleitte ik de wenselijkheid van het ontstaan van speech and hearing centra in Nederland. Om vele redenen handhaaf ik heden nog dit standpunt en men ziet ook dat dit standpunt steeds meer terrein wint, daar de bestaande audiologische centra steeds meer kinderen en volwassenen met spraak- en taalstoornissen begeleiden, 
omdat de logopedische centra mede vanwege de bezuinlgingen nog steeds niet officieel erkend zijn en daardoor verdwijnen. Gezien de dagelijkse praktijk binnen de audiologische centra is het mljns inziens verstandig de naam audiologisch centrum in Nederland te veranderen in centrum voor spraak- en gehoorgestoorden.

De spraak-taalpatholoog en de foniator spelen binnen de keel-, neus- en oorheelkunde zeker in de universitaire centra een steeds belangrijkere rol dan voorheen. De problemen betreffende spraak- en taalstoornissen laat ik, gezlen mijn inaugurele rede, heden onbesproken. De fonlater otwel de stemspecialist houdt zich bezig met de pathogenese, de pathologie en therapie van patiennten met stemstoornissen. Ais ik vermeld, dat het stemorgaan bestaat uit een actuator (de longen), de generator (de larynx) en de resonator (de pharynx, mondholte, neus en neusbijholten) zult u dit begrijpen. Daarnaast speelt het gehoor een belangrijke rol bij de terugkoppeling van het stemgeluid.

$\mathrm{Na}$ het afnemen van de anamnese blj een patiënt met een stemstoornls en een stemtechnlsch onderzoek waarblj de fonatiestijl, de fonatleprestatie en de kwaliteit van de stem worden onderzocht, volgt een fysisch-dlagnostlsch onderzoek, dat naast een algemeen keel-, neus- en oorheelkundlg onderzoek bestaat uit een uitgebreid onderzoek van de larynx en bovendien, indien nodig, uit een longonderzoek. De klinische laryngologie ontstond nadat Manuel Garcia in 1854 door middel van een splegel en het daarop vallend zonlicht de stembanden zlchtbaar maakte. Het zijn daarna Czermak en Türck geweest die in 1858 de spiegel in de kliniek voor het onderzoek van de larynx voor het eerst toepasten, de zgn. indirecte laryngoscople. De indirecte laryngoscopie met behulp van een stroboscopische lichtbron, waardoor een beeld verkregen wordt van het triilingspatroon van de stembanden, komt na 1950 tot ontwikkeling. In 1960 schreef Schönärl de eerste monografie over de klinische toepassingen van het stroboscopisch onderzoek. Omdat de stembandtrilling via deze methode van onderzoek in vertraagde vorm waarneembaar is, kunnen stembandsluiting en vormafwijkingen In detail worden bestudeerd. Deze methode van onderzoek van de larynx is gedurende de afgelopen jaren zeer waardevol gebleken.

De directe laryngoscople werd door Klllian in Freiburg in 1911 geïntroduceerd. De larynx werd door hem via een korte buls bij de patient in rugligging direct in beeld gebracht. Scalco uit New Orleans introduceerde in 1963 bij deze vorm van laryngoscopisch onderzuek het gebrulk van de operatlemicroscoop. 
Ongetwijfeld moet in dit verband ook de naam van Kleinsasser genoemd worden, die in 1963 betreffende deze methode de praktische toepassing beschreef van de chirurgische behandeling van diverse goedaardige afwijkingen aan de stembanden. De starre directe laryngoscople biedt bovendien de mogelijkheid tot fotografie en videoregistratie. Ook bij stemstoornissen, al dan niet een gevolg van verkeerd stemgebrulk, kan een chirurgische ingreep aangewezen zljn. Voor dergelijke ingrepen bestaat als verzamelnaam de fonochirurgie (Hirano, 1972; Bouche, 1973; Isshiki, 1980).

Tenslotte is van belang te vermelden, dat voor poliklinisch gebruik de directe laryngoscopie door middel van een flexibele laryngoscoop onmisbaar is geworden.

\section{Oncologie}

De incidentie van maligne hoofd-halstumoren, waartoe de tumoren boven het niveau van de sleutelbeenderen worden gerekend - uitgezonderd de tumoren van de schedelinhoud - bedraagt In Nederland 23 per 100.000 inwoners per jaar. Dit betekent, dat er jaarlijks in Nederland bij ongeveer 3.500 personen een maligniteit in het hoofd-halsgebied wordt vastgesteld. Hiervan worden ongeveer 2.200 patlënten met radiotherapie behandeld en de overige 1.300 behoeven een chirurgische behandeling, welke in de meeste gevallen op universitair niveau plaatsvindt. Dit heeft tot gevolg, dat in de universitaire KNO-afdellngen zoveel patiënten met hoofd-halstumoren zijn opgenomen, dat de wachtlijsten van patiënten met overige KNO-afwijkingen toenemen. Veel tijd en energie wordt aan de behandeling Inclusief verpleging en revalidatie van deze patiënten besteed. Het is voor het eerst in 1989 gelukt, dat het landelijk overlegorgaan kankercentra (het zgn. LOK) een voor $100 \%$ sluitende registratie van patiënten met hoofd-halstumoren bereikte. Tevens is belangrijk te vermelden dat in 1978 het zgn. TNM-systeem wereldwijd werd aanvaard, een classificatiesysteem dat exact de uitbreiding van de tumor, de locoregionale lymfklieren en de metastasen op afstand beschrijft. Ik noemde reeds de vooruitgang in de beeldvormende technieken, de CT-scan en MRI. Ook is het nodig het ontstaan te memoreren van de vaak toegepaste punctie-cytologie, te danken aan een team cytologen verbonden aan het radiotherapeutisch instituut Radihemmet te Stockholm. In 1960 ontwierp Franzén hiervoor een spuit met speciale handgreep, waardoor het mogelijk is de spuit met éen hand 
vast te houden en de zuiger terug te trekken, waardoor de andere hand steeds beschikbaar is om de te puncteren weerstand te fixeren. Naast de vooruitgang in de chirurgische technieken, waaronder de partlële larynxextlrpatie en supraglottische larynxextirpatie volgens Ogura (1958), de reconstructieve chirurgie door middel van myocutane lappen (Bakamjian, 1965), de laserchirurgie (Yako, 1970) en het overbrengen van vrije transplantaten, al of niet gevasculariseerd,in het operatieterrein, noem ik tenslotte nog het tot ontwikkeling komen van de diverse cytostatica bij de behandeling van deze patiënten.

Bljna aan het einde gekomen van deze rede, besef ik vanzelfsprekend dat het besprokene slechts een schets is betreffende de vooruitgang in de keel-, neus- en oorheelkunde gedurende mijn periode als specialist. Wellicht hadden de insiders onder de toehoorders op andere feiten de nadruk gelegd. Zo kwam bijvoorbeeld de broncho-oesophagologie niet aan de orde. Het zi] mij vergeven.

De verschillende subspecialismen binnen de keel-, neus- en oorheelkunde kwamen echter aan de orde. In 1988 werd de opleiding tot keel-, neusen oorarts in Nederland terecht verlengd van vier tot vijf jaar. In Europees verband vindt reeds een discussie plaats over een opleidingsduur in de keel-, neus- en oorheelkunde van 6 jaar bestaande uit een basisopleiding van vier Jaar gevolgd door een verdere specialisatie in de otologie, rhinologie en laryngologle gedurende twee jaar. Een verdere differentiatie binnen de keel-, neus- on oorheelkunde, in mijn rede in 1970 voorzien, gaat ongetwijfeld ook in de toekomst door. De consequenties terzake die ongetwijfeld een gevolg hiervan kunnen zijn laat lk echter aan de toekomst over.

Tenslotte beëindig ik deze rede gaarne met het uitspreken van enkele dankwoorden tot degenen die voor mij van bijzondere betekenis zijn geweest in mijn periode ais specialist. Dit geldt allereerst voor mijn leermeester Brinkman. Voor mil is hij altjjd een vaderlijke vriend geweest die mij in mijn Nijmeegse periode steeds in alle opzichten de gelegenheid gaf tot verdere ontplooilng. Bovendlen was hij, tezamen met Jonkees, extern adviseur van onze medische faculteit bij de oprichting van onze vakgroep te Maastricht. Ik denk daarbij eveneens met genoegen terug aan zijn medewerkers van den Broek, Wentges, van Baarle en Kuypers. 
Ik dank eveneens gaarne mljn collegae hoogleraren in de keel-, neusen oorheelkunde in Nederland voor hun vertrouwen en steun blj de opbouw van onze afdeling in Maastricht. Ditzelfde geldt voor het bestuur van de Stichting Het Heinsius Houbolt Fonds. Dankzij de financiële steun van deze stichting kwam het wetenschappelijk onderzoek, waaronder de promotie van van den Berge, in de otologle tot stand.

Met moeite neem ik afscheid van deze universiteit en van het fraale njeuwe academische zlekenhuis. Het bestuur, mijn collegae, mijn medewerkers van beide instellingen, dank ik zeer voor de prettige en vruchtbare samenwerking gedurende de laatste jaren.

Vanzelfsprekend gaat mijn bijzondere dank uit naar de stafleden van de afdeling keel-, neus- en oorheelkunde to Maastricht. Tezamen voor jullie voortdurende en steeds meer verantwoordelijke zorg voor onze patiënten dank ik jullie eveneens voor jullie bijdragen in het onderwljs aan onze studenten en het wetenschappelijk onderzoek. Ook het postgraduate onderwijs had jullie grote belangstelling. ik denk daarbij aan de internationale nascholingscursussen vestibulologie, de kliniek voor stemstoornissen, de 'Facial plastic and reconstructive surgery' symposia en de meeting van de Politzer Soclety. Jullie steun, jullie vriendschap, en jullie vertrouwen In mij bracht dit alles tot stand. Hlervoor mijn oprechte dank. Ook mijn oud-stafleden: Laumans, Kahman, de Jong en Zijlker, de oud-assistenten, de collegae keel-, neus- en oorartsen in de regio en huisartsen vergeet ik niet. Voor hen geldt dit dankwoord eveneens. Hetzelfde geldt voor de huidige assistenten in opleiding en alle overige medewerkers van de afdeling keel-, neus- en oorheelkunde te Maastricht. Hun hulp is dagelijks onmisbaar en werd door mij dan ook dagelljks gewaardeerd.

Tenslotte dank ik ook mijn ouders, mijn vrouw Catrien, mijn kinderen en kleinkinderen. Wat ik in mijn werk heb bereikt, is ongetwijfeld, en lk zeg dit met nadruk, aan ons harmonieus gezinsleven - eveneens gedurende 35 jaar to danken.

Ik heb gezegd. 